\title{
Clinical examination of lipohypertrophy: Best practice recommendations
}

\section{Author}

Carole Gelder

Childrens Diabetes Nurse Specialist (Leeds Childrens'

Hospital) and Lecturer (University of York)

\section{Objectives}

Forum for Injection Technique (FIT) recommendations for lipohypertrophy $(\mathrm{LH})$ detection influenced clinical examination technique with the aim of improving practice and health outcomes for children and young people (CYP).

\section{Method}

Interactive LH workshops were developed to influence a change in care provision and facilitate swift integration into clinical practice. The events were delivered to the Leeds children's diabetes team and to a representative from each of the Yorkshire and Humber (Y\&H) CYP Diabetes Network.

A structured clinical examination was role modelled, facilitated by four young male volunteers with diabetes. Two YP managed their diabetes on a multiple daily injection regime (MDI) and two were on continuous subcutaneous insulin infusions (CSII).

Opportunity to visualise and palpate injection sites for LH outwith the pressured clinic environment was universally appreciated by all attendee's. The use of head torches, safe skin marker pens, and use of gel in liberal amounts was widely agreed to be important in detection of LH.

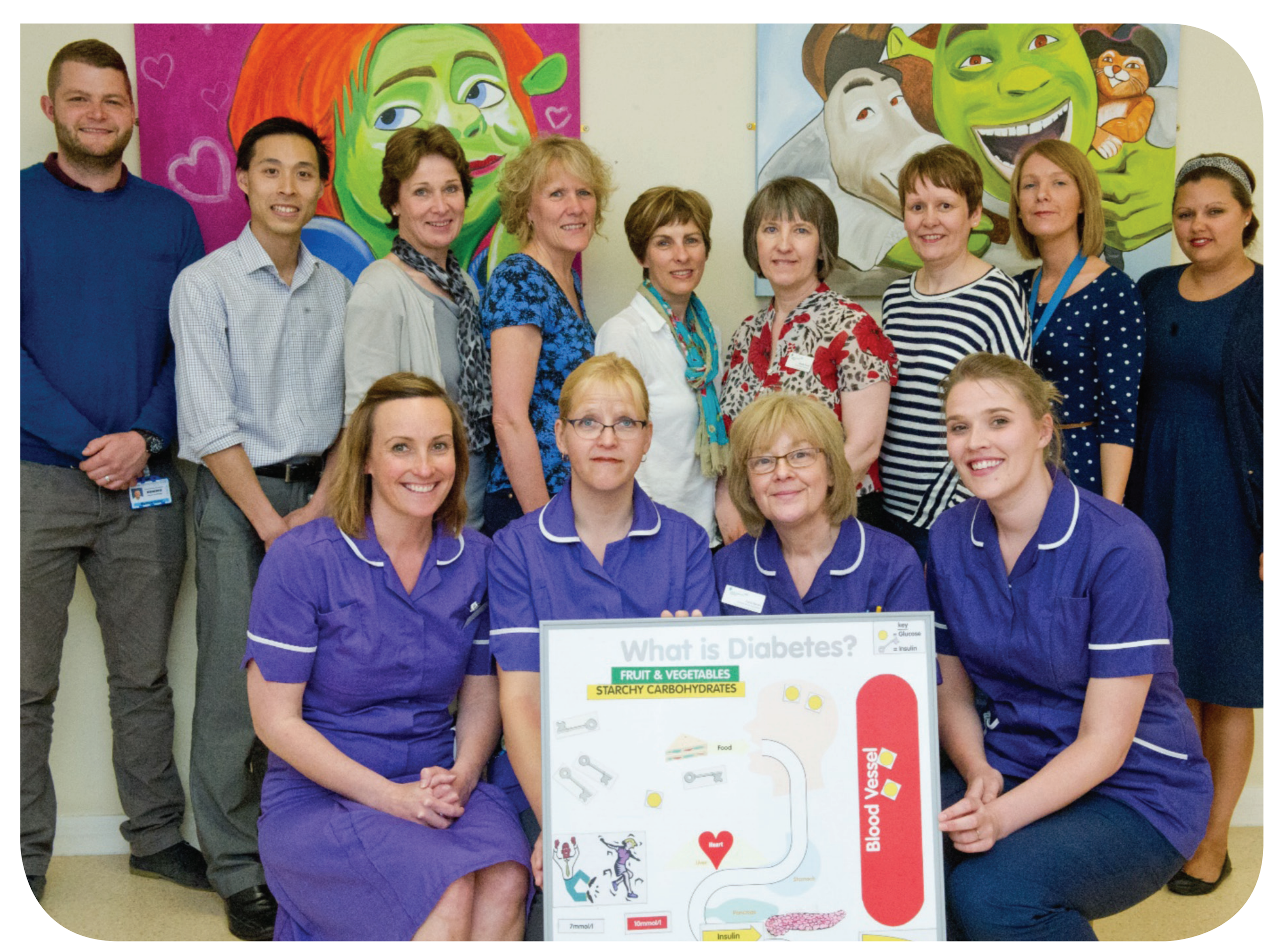

\section{Results}

Encouragement to examine more firmly using two fingers at a 30 degree angle facilitated identification of $\mathrm{LH}$. Distinguishing a change in skin texture from softer smoother areas to harder more rubbery skin texture and locating transition zones also formed part of the examination method. Both medical and nursing colleagues reported increased expectation to find $\mathrm{LH}$ as well as confidence using an agreed method of best practice.

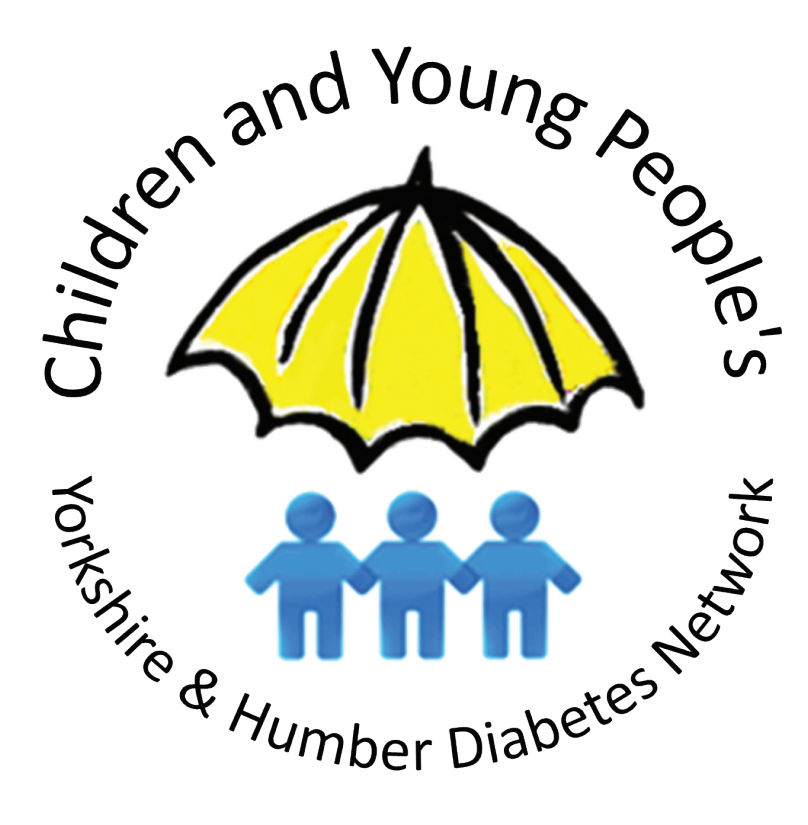

Although the number of volunteers was small a difference in the shape and formation of $\mathrm{LH}$ in patients on CSII (more diffuse and uneven) compared to those on MDI (more localised and discrete) was also observed and may have implications for clinical practice.
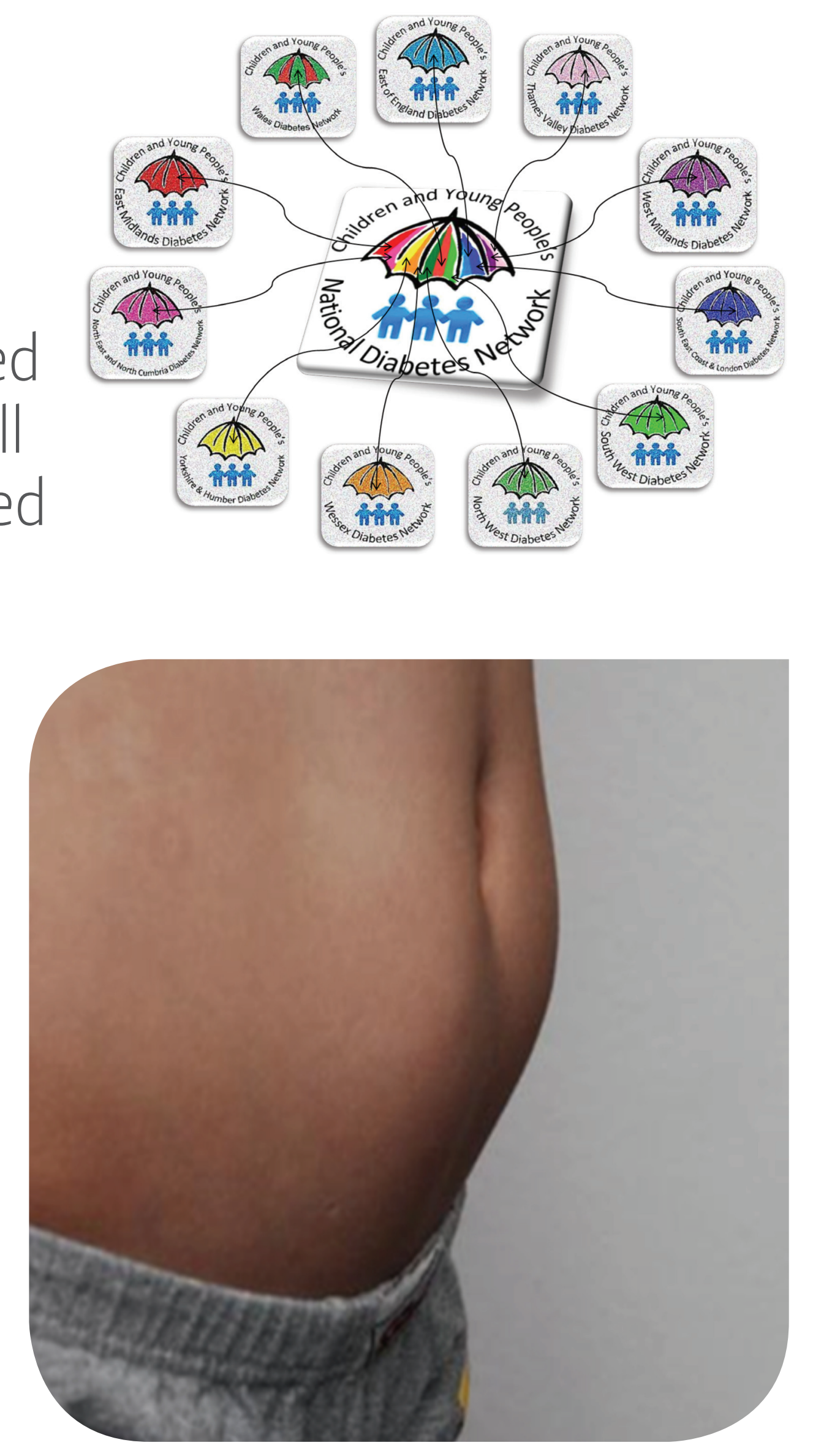

\section{Conclusion}

Health care professional's reflection on practice and agreement of tangible changes in detection technique for LH has the potential to reduce glycaemic variation and hypoglycaemia.
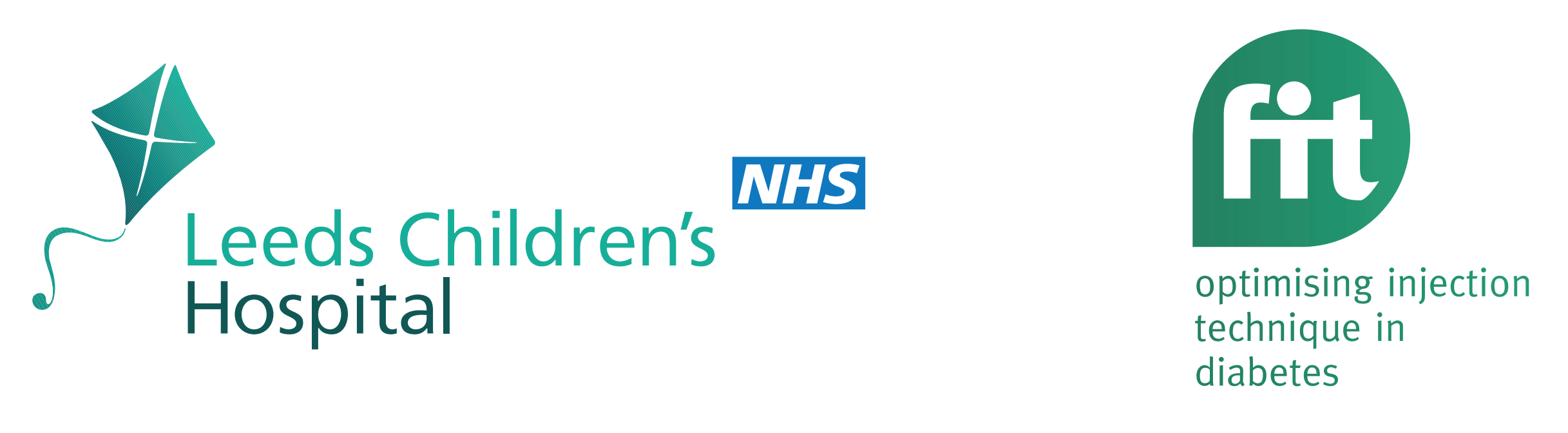